\title{
Research on Optimal Allocation of Water Resources in Binzhou Based on Sustainable Development
}

\author{
Jinfang Sun, Miaomiao Cui, Hui Liang, Long Han ,Wei Liu \\ Architectural Engineering Department, Binzhou Polytechnic, Binzhou 256603, China \\ Email: sdsjf722@sina.com
}

Keywords: Water resources; Cities; Sustainable development; Optimal allocation

\begin{abstract}
Sustainable utilization of water resources in Binzhou was studied through the ecological footprint theory.All kinds of water resources were ecological surplus in 2012.The production water surplus was the largest, which was $0.1370 \mathrm{hm}^{2}$ per capita.The ecological water surplus was the smallest, which was $0.0040 \mathrm{hm}^{2}$ per capita.The total ecological surplus was $0.1498 \mathrm{hm}^{2}$ per capita.This indicated that the water resources utilization of Binzhou was sustainable.The optimal allocation of water resources of Binzhou was studied through the model. By 2020, the main water used in Binzhou will be agriculture, accounting for $72 \%$.The followed is industry water, accounting for $17 \%$. The proportion of living water and ecology water are $7 \%$ and $4 \%$ respectively. By 2030 , the main water used in Binzhou will be still agriculture.The proportion falls down to $66 \%$.The industry water increase greatly.The proportion of ecology water will not increase obviously, but the amount increases. At the end of this paper, suggestions for sustainable utilization of water resources was proposed.This paper has a great significance for the exploitation and utilization of water resources in local cities.
\end{abstract}

With the development of economy and the fast advance of urbanization, the demand of water resources had increased sharply, and water pollution was also getting worse. The contradiction between water supply and demand becomed increasingly acute, which had been an important factor restricting sustainable development of cities. Based on the theory of ecological footprint, this paper researched the ecological footprint and carrying capacity of water resources in Binzhou in 2012. It calculated ecological profit and loss, objectively evaluated sustainable utilization of water resources, and optimally allocated the limited water resources.This paper can provide datas for local government to make plans of water resources development.

\section{Evaluation of the sustainable use of water resources}

Concept of ecological footprint was firstly proposed by Willian Rees in 1992,which was an ecological economist from Canadian ${ }^{[1]}$. It compares the resource and energy consumption of a country or area with its ecological capacity,and then determines whether the development of a country or region is within the scope of ecological carrying capacity . This theory has been accepted by scholars and widely applied since it was put forward ${ }^{[2-4]}$. This paper researched the sustainable utilization of water resources in Binzhou in 2012 by the ecological footprint models from the reference $^{[5]}$. The basic datas of living water,production water, ecological water, population and GDP are from Shandong Statistical Yearbook ${ }^{[6]}$.

\subsection{Ecological footprint of water resources}

The results of ecological footprint of water resources in Binzhou in 2012 were shown in Table 1. As can been seen, ecological footprint of production water was the largest, which was $1.105 \mathrm{hm}^{2}$ per capita.The followed was ecological footprint of living water,which was $0.071 \mathrm{hm}^{2}$ per capita.The ecological footprint of ecological water was the smallest,which was $0.032 \mathrm{hm}^{2}$ per capita.This indicated that the major water resources of the city was used for industry and agriculture. 
Tab.1 The results of ecological footprint in Binzhou in 2012

\begin{tabular}{cccccc}
\hline & Consumption $/ 10^{8} \mathrm{~m}^{3}$ & $\gamma_{w}$ & $\mathrm{Pw}\left(\mathrm{m}^{3} / \mathrm{hm}^{2}\right)$ & $\mathrm{EF} / \mathrm{hm}^{2}$ & $\mathrm{ef} / \mathrm{hm}^{2}$ per capita \\
\hline Living water & 0.91 & 5.19 & 1750 & 269880 & 0.071 \\
Production water & 14.11 & 5.19 & 1750 & 4184623 & 1.105 \\
Ecological water & 0.41 & 5.19 & 1750 & 121594 & 0.032 \\
$\quad$ Total & 15.43 & & & 4576097 & 1.208 \\
\hline
\end{tabular}

\subsection{Ecological carrying capacity of water resources}

The results of ecological carrying capacity of water resources in Binzhou in 2012 were shown in Table 2. The ecological carrying capacity of production water was the largest,the living water was the second,and the ecological water was the smallest.The total ecological carrying capacity was $1.357 \mathrm{hm}^{2}$ per capita.

Tab.2 The results of ecological carrying capacity of water resources in Binzhou in 2012

\begin{tabular}{cccccrc}
\hline & $\mathrm{W} / 10^{8} \mathrm{~m}^{3}$ & $\gamma_{w}$ & $\mathrm{y}_{\mathrm{w}}$ & $\mathrm{P}\left(\mathrm{m}^{3} / \mathrm{hm}^{2}\right)$ & $\mathrm{EC}\left(\mathrm{hm}^{2}\right)$ & ec/ $\mathrm{hm}^{2}$ per capita \\
\hline Living water & 0.91 & 5.19 & 2.81 & 1750 & 303345 & 0.08 \\
Production water & 14.11 & 5.19 & 2.81 & 1750 & 4703516 & 1.241 \\
Ecological water & 0.41 & 5.19 & 2.81 & 1750 & 136672 & 0.036 \\
$\quad$ Total & 15.43 & & & & 5143533 & 1.357 \\
\hline
\end{tabular}

\subsection{Ecological surplus or deficit of water resources}

The results of ecological surplus or deficit of water resources in Binzhou in 2012 were shown in Table 3. As can be seen, all water resources in Binzhou were ecological surplus. The largest surplus was production water for $0.1370 \mathrm{hm}^{2}$ per capita, and the smallest surplus was cological water for $0.0040 \mathrm{hm}^{2}$ per capita. The total surplus was $0.1498 \mathrm{hm}^{2}$ per capita.This indicated that the water resources exploitation in Binzhou was sustainable in 2012. The living and ecological environment was looked after when the economy was developed.

Tab.3 The results of ecological surplus or deficit in Binzhou in 2012

\begin{tabular}{ccc}
\hline & $\mathrm{ER}_{\mathrm{d}} / \mathrm{hm}^{2}$ & $\mathrm{er}_{\mathrm{d}} / \mathrm{hm}^{2}$ per capita \\
\hline Living water & -33465 & -0.0088 \\
Production water & -518893 & -0.1370 \\
Ecological water & -15078 & -0.0040 \\
Total & -567436 & -0.1498 \\
\hline
\end{tabular}

\section{Optimal allocation of water resources}

The optimal allocation of water resources should not only follow the rules of the market, but also be regulated by administrative, economic and legal means. The principles for the optimal allocation of water resources were as follows:

(1) The principle of priority in life. Water resources should be supplied for living demand firstly, taking into account agricultural, industrial and ecological water demand.

(2) The principle of total volume control. Measures should be implemented to control the total volume of water resources,such as planned water use, water quality separation,water conservation and coordinated water supply among different departments. 
(3) The principle of efficiency. The quantity and effectiveness of water involved in agriculture, industry, living and ecology should be increased, and the inefficient evaporation during water conversion and consumption should be reduced.

(4) The sustainable development principles. We should ensure not only the present generation benefits consuming water resources but also the equal rights enjoying by future generation.

(5) The principles of reasonable pricing and tilt pricing. Different prices should be set according to different industries and uses.

\subsection{Target function}

(1) Economic objective: Considering the economic benefit of unit water supply, we should obtain more economic benefit with less water through water-saving of industry and agriculture.

$$
\max f_{1}(x)=\sum_{j=1}^{J} \sum_{i=1}^{I}\left(b_{i j}-c_{i j}\right) x_{i j}
$$

In the above formula, $x_{i j}$ was water supply from headwater $\mathrm{i}$ to user $\mathrm{j}, b_{i j}$ was efficiency factor of unit water supply from headwater $i$ to user $j, c_{i j}$ was cost factor of unit water supply from headwater $i$ to user $j, I$ and $J$ were headwater numbers and user numbers separately.

(2)Social objective: Considering the social stability, we should ensure that most areas and users don’t enjoy water shortage.

$$
\min f_{2}(x)=\sum_{j=1}^{J}\left[D_{j}-\sum_{i=1}^{I} x_{i j}\right]
$$

In the above formula, $D_{j}$ was total water demand of user $j$.

(3)Environmental objective: Considering environment protection,we should emit less pollutants.

$$
\min f_{3}(x)=\sum_{j=1}^{J} 0.01 d_{j} p_{j} \sum_{i=1}^{I} x_{i j}
$$

In the above formula, $d_{j}$ was concentration of per unit pollutant of user $j$,COD was the key pollutant indicator, $p_{j}$ was sewage discharge factor of user $j$ 。

\subsection{Constraints}

(1) Water demand constraints: Total water use for agriculture, industry, liveling and ecology should be less than total water supply.

$$
\sum_{j=1}^{J} x_{i j} \leq Q_{i}
$$

In the above formula, $Q_{i}$ was the availability of headwater $i$.

(2) Water supply constraints: The water supply of users should be between the minimum and maximum of water requirements.

$$
W_{\mathrm{j}, \min } \leq \sum_{\mathrm{i}=1}^{\mathrm{I}} \boldsymbol{x}_{i j} \leq \boldsymbol{W}_{\mathrm{j}, \max }
$$

In the above formula, $W_{j, \min }$ and $W_{j, \max }$ were the minimum and maximum of water requirements of user $j$ separately.

(3) Non-negative constraints

$$
x_{i j} \geq 0
$$

\subsection{Results and analysis}

Through the target function and constraints we can make optimal allocation of water resources. The results of optimal allocation of the various water sources in sectors was calculated by Matlab software in Binzhou by 2020 and 2030 , as shown in Table 4. 
Tab.4 The results of optimal allocation of water sources in Binzhou $/ 10^{9} \mathrm{~m}^{3}$

\begin{tabular}{ccccccc}
\hline Planned year & Headwaters & Living & Industry & Agriculture & Ecology & Total \\
\hline \multirow{2}{*}{2020} & Surface water & 1.36 & 0.63 & 10.79 & 0.73 & 13.51 \\
& Groundwater & 0.37 & 0.42 & 0.78 & 0.28 & 1.85 \\
& Others & 0 & 0.83 & 0 & 0.12 & 0.95 \\
& Total & 1.73 & 1.88 & 11.57 & 1.13 & 16.31 \\
& Surface water & 1.56 & 0.79 & 10.67 & 1.27 & 14.29 \\
& Groundwater & 0.52 & 0.47 & 0.65 & 0.39 & 2.03 \\
& Others & 0 & 1.23 & 0 & 0.14 & 1.37 \\
& Total & 2.08 & 2.49 & 11.32 & 1.8 & 17.69 \\
\hline
\end{tabular}

It can be seen from Table 4,the main water by 2020 in Binzhou will be agriculture water with $72 \%$, followed by industry water with $17 \%$, which increase relative to current levels.The proportion of living water and ecology water are $7 \%$ and $4 \%$ respectively with little change. The main water by 2030 in Binzhou will still be agriculture water, which the proportion will fall to $66 \%$. Industrial water will increase largerly, and ecology water will not increase. However,the amount of ecology water will increase due to increase of the total water amount by 2030.This shows the synchronization of ecology protect and industry growth.

\section{Conclusions and suggestions}

From above analysis,we reached the following conclusions:

(1)All kinds of water resources were ecological surplus in 2012.The production water surplus was the largest,which was $0.1370 \mathrm{hm}^{2}$ per capita.The ecological water surplus was the smallest, which was $0.0040 \mathrm{hm}^{2}$ per capita.The total ecological surplus was $0.1498 \mathrm{hm}^{2}$ per capita.

(2)The results of optimal allocation of water resources showed that the main water used by 2020 in Binzhou will be agriculture, accounting for $72 \%$.The followed is industry water, accounting for $17 \%$. The proportion of living water and ecology water are $7 \%$ and $4 \%$ respectively. By 2030 , the main water used in Binzhou will be still agriculture. The proportion falls down to 66\%.The industry water increases greatly.The proportion of ecology water will not increase obviously, but the amount increases. This shows the synchronization of ecology protect and industry growth.

The sustainable use of water resources can be achieved through the following ways:

(1) We can develop new type of circular economy,increase the utilization rate of resource circulation, and transform the old and new kinetic energy.We can update industrial production processes, strictly examine and approve new projects, control the total amount of pollutants, and vigorously develop industry and agriculture ecology parks.

(2) We can promote energy conservation and emission reduction, adjust the industrial structure, and develop new technology industries.We can upgrade and transform traditional industries, and improve the mechanism of supervision, reward and punishment.

(3) We can develop and utilize water resources reasonably based on principles of reasonable economic soundness and feasible technology. Under the premise of meeting needs of economic development, it is necessary to avoid emergence of environmental problems. We should formulate measures to protect water resources and build water-saving projects.

(4) Urban sewage can be becomed resources to utilized.We should develop or introduce advanced technologies and deeply treat urban sewage.The research on seawater desalination technology and rainwater collection and reuse should be speeded up.It can be reused more widely involving agriculture, industry, landscape and municipal water. The water costs will be reduced.

\section{Acknowledgements:}

Research on the ecological greening of saline and alkaline areas in the Yellow River delta（2015ZC0122） 


\section{References}

[1]Lu Yuan,Hua Cui.Ecological footprint dynamic analysis of Guangxi Zhuang Autonomous Region,from 1990 to 2002[J].China population,resources and environment,2004,14(3) : 49- 53.

[2]Ferng J J.Using composition of land multiplier to estimate ecological footprints associated with production activity[J].Ecological Economies,2001(37):159-172.

[3]Lenzen M,Murray S A. A modified ecological footprint method and its application to Australia[J]. Ecological Economics,2001(37):229- 255.

[4]Haberl H,Erb K H, Krausmann F.How to calculate and interpret ecological footprints for long periods of time: the case of Australia 1926-1995[J].Ecological Economics,2001(38):25- 45.

[5]Tang Guanhua,Liu Yong.Research on ecological capacity of water resources in Zhejiang Province based on ecological footprint model[J].Zhejiang Hydrotechnics,2013(1):45-47.

[6]Shandong Province Statistics Department. 《 Shandong Statistical Yearbooks 》 (2001 2013)[M].Beijing: China Statistical Press,2002 2014. 